\title{
Determination of Residual Stress and Critical Rolling Tempera- tures in a Microalloyed Steel with Low Carbon and Niobium Con- tents
}

\author{
Gómez, Manuel; Hernanz Oscar, Medina Sebastián F.;Tarín Pascual
}

Using torsion tests, residual stress $(\Delta \sigma)$ and critical rolling temperatures $\left(T_{n r}, A_{r 3}, A_{r 1}\right)$ have been determined for a low Nb content microalloyed steel by means of simulation of rolling cycles and subsequent representation of mean flow stress versus the inverse of the temperature. The above magnitudes were determined as a function of interpass time for two strains applied in each pass $(0.20,0.35)$, respectively. Among the results found, it is notable that $\Delta \sigma$ decreases with longer interpass times until it reaches zero, and is greater the smaller the strain applied. With regard to the cooling transformation temperatures $A_{r 3}$ and $A_{r 1}$, these were found to be practically independent of the interpass time and were higher for smaller applied strains. Temperatures $A_{r 3}$ and $A_{r 1}$ were also determined by dilatometry, and comparison of these values showed that both methods yield similar results, except in the value of $A_{r 1}$

Ermittlung von Restspannung und kritischer Walztemperatur eines mikrolegierten Stahls mit niedrigem Kohlenstoff- und Niob-Gehalt. Mit Hilfe von Torsionsprüfungen wurden Restspannung $(\Delta \sigma)$ und kritische Walztemperaturen (Tnr, Ar3, Ar1) eines mikrolegierten Stahls mit niedrigem Gehalt an Nb ermittelt. Hierzu wurden Walzzyklen simuliert und anschließend die Flussspannung im Verhältnis zur invertierten Temperatur dargestellt. Die oben angeführten Größen wurden als Funktion der Zeit zwischen zwei Walzstichen für zwei in jedem Walzstich ausgeübte Verformungsbelastungen $(0,20$ bzw. 0,35) ermittelt. Bei den festgestellten Ergebnissen erwies sich als bemerkenswert, dass $\Delta \sigma$ mit zunehmender Zeit zwischen zwei Walzstichen bis auf Null abnimmt und umso höher liegt, je geringer die ausgeübte Verformungsbelastung ist. Was die Umwandlungstemperaturen Ar3 und Ar1 beim Abkühlen betrifft, verhielten sich diese praktisch unabhängig von der Zeit zwischen zwei Walzstichen und lagen umso höher, je niedriger die Verformungsbelastung war. Zusätzlich dazu wurden die Temperaturen Ar3 und Ar1 auch durch Dilatometrie ermittelt; der Vergleich dieser beiden Werte ergab, dass mit Ausnahme des Wertes von Ar1 bei beiden Methoden ähnliche Ergebnisse erzielt werden.

Cooling transformation temperatures $\mathrm{A}_{\mathrm{r} 3}$ and $\mathrm{A}_{\mathrm{r} 1}$ are, together with the no-recrystallisation temperature $\mathrm{T}_{\mathrm{nr}}$, considered to be critical in hot rolling. The parameter $\mathrm{T}_{\mathrm{n}}$, defined as the temperature at which static recrystallisation starts to be inhibited in hot rolling, is of great importance as it influences the austenite microstructure at the end of rolling, completely or partially recrystallised or completely strengthened. The phase transformation temperatures $A_{r 3}$ and $A_{r 1}$ are also important since their values indicate the temperature limits between which rolling will be performed, either in the austenitic region or in the intercritical region.

The parameter $T_{n r}$ can be determined by simulation of several rolling passes and subsequent graphic representation of mean flow stress (MFS) versus the inverse of the temperature for each pass [1...4]. $A_{r 3}$ and $A_{r 1}$ can be determined simultaneously with $T_{n r}$ using the same method, i.e. from the graphs that represent MFS versus $1 / T$, [5...9] or by other methods such as the dilatometry technique. The latter is a classic method which offers very good precision.

On the other hand, it is well known that the value of $\mathrm{T}_{\mathrm{nr}}$ depends on the chemical composition of the steel, the equivalent strain applied in each pass, the strain rate and the interpass time $(\Delta t)$. [3; 5] For their part, temperatures $A_{r 3}$ and $A_{r 1}$ are dependent on the chemical composition of the steel and the austenite microstructure (grain size, strengthening) before the start of the $\gamma \rightarrow \alpha$ transformation, and are easier to determine the lower the carbon content, especially when the technique used is representation of MFS versus 1/T. [1]

Besides these critical temperatures, another important objective of this work is to determine in the same simulation test the residual stress accumulated in the austenite when the temperature drops below $\mathrm{T}_{\mathrm{n}}$, as well as the influence of the deformation variables on residual stress. It should be noted that the accumulated strengthening of austenite at temperatures below $\mathrm{T}_{\mathrm{nr}}$ has been characterised by other authors, [11; 12] determining the strain accumulated in successive passes, which was measured by these authors "in terms of the specific austenite grain boundary area prior to transformation, from specimens quenched after the finishing deformation".

This paper therefore proposes a quick and direct method for measuring residual stress simultaneously with the determination of critical temperatures, allowing it to be measured in each pass by means of a simple geometric composition on the graphic representation of MFS versus the inverse of the temperature. While a brief application of this method has recently been reported, [13] this paper presents a more exhaustive application representing residual stress versus interpass time and the strain applied in each pass.

Finally both the accumulated strain and accumulated stress, referred to in this work as residual stress $(\Delta \sigma)$ by allusion to the stress accumulated just before the temperature $A_{r 3}$ is reached, represent the appropriate magnitude for relating the state of the austenite microstructure before the start of the $\gamma \rightarrow \alpha$ transformation with the final fer- 
rite grain size. $[14 ; 15 ; 16]$ In the opinion of the authors of this work, the use of residual stress offers important advantages, since, as will be seen below, it is a magnitude that can be directly measured without the need for measurements of the size and lengthening of the austenite grain.

\section{Experimental procedure}

The chemical composition of the microalloyed steel studied is shown in table 1. This is a steel with low carbon and niobium contents and a relatively high nitrogen content. Once strain-induced precipitation has started, either during rolling or in the simulation tests, the low $\mathrm{Nb} / \mathrm{N}$ percentage ratio close to 1 and the even lower $\mathrm{Nb} / \mathrm{C}$ ratio should favour the formation of small precipitates due to the low dissolved $\mathrm{Nb}$ content in equilibrium compared with the $\mathrm{C}$ and $\mathrm{N}$ contents. [17].

Thermomechanical simulation has been carried out by multipass torsion tests. The specimens had a diameter of $6 \mathrm{~mm}$ and a gauge length of $50 \mathrm{~mm}$. The reheating temperature was $1250^{\circ} \mathrm{C}$ and the holding time at this temperature was $10 \mathrm{~min}$. These conditions were sufficient to achieve complete dissolution of the precipitates, i.e. for the carbonitride-forming elements ( $\mathrm{Nb}, \mathrm{C}, \mathrm{N}$ ) to be fully dissolved. [18] The temperature was then rapidly lowered to that corresponding to the first pass $\left(1150^{\circ} \mathrm{C}\right)$, establishing a cooling rate of $25^{\circ} \mathrm{C}$ between successive passes until the final pass, which was made at $675^{\circ} \mathrm{C}$. Several simulations were performed for different values of $\Delta \mathrm{t}(20,30$, $60,100,200,500 \mathrm{~s})$ and two strains of 0.20 and 0.35 . The strain rate was the same $\left(3.43 \mathrm{~s}^{-1}\right)$ for all the deformation conditions.

The specimens for dilatometry tests had a diameter of $2 \mathrm{~mm}$ and a length of $12 \mathrm{~mm}$. During the test they were protected from oxidation by a vacuum of the order of $10^{-5} \mathrm{MPa}$. Both heating and cooling were carried out at a constant rate previously programmed using the test software. The rates applied were $1.25,0.84,0.42$ and $0.25 \mathrm{~K} / \mathrm{s}$, which are similar to the cooling rates applied in the aforementioned thermomechanical simulation tests corresponding to interpass times of 20,30,60 and 100 s, respectively. The austenitisation temperature was always $1000^{\circ} \mathrm{C}$ and the holding time was $2 \mathrm{~min}$.

\section{Results and discussion}

The magnitudes of torsion (torque, $\mathrm{n}^{\circ}$. of revolutions) and the equivalent magnitudes (stress, strain) have been related according to Von Mises criterion. [19] In this way it is possible to draw stress-strain curves and to calculate the MFS for each pass and its subsequent representation as a function of the inverse of the temperature.

Flow curves and MFS versus 1/T. Determination of critical parameters $\left(T_{n r}, \Delta \sigma, A_{r 3}, A_{r 1}\right)$. Figures 1 and 2 show two examples of thermomechanical simulations with different values of $\Delta t$ and strain applied in each pass. In figure 1, prepared for a $\Delta \mathrm{t}$ of $20 \mathrm{~s}$ and a strain of 0.20 , the value of the maximum stress reached in each pass shows with good approximation those passes where it is presumed that changes have occurred which give rise to different microstructures in the evolution of the austenite and its subsequent transformation to ferrite. However, in figure 2, prepared for a $\Delta \mathrm{t}$ of $200 \mathrm{~s}$ and a strain of 0.35 , it is not possible to clearly observe the step where $\mathrm{T}_{\mathrm{nr}}$ could be defined, and as will be seen below this is precisely due to the fact that the rolling conditions applied allowed the austenite to recrystallise completely between successive passes (static recrystallisation), practically until the temperature $A_{r 3}$ was reached, which can easily be observed by a notable drop in the maximum stress.

The critical temperatures are better observed in figures 3 and $\mathbf{4}$, which represent MFS versus 1/T. The value of MFS is determined in each pass, given by the area of the corresponding stress-strain curve, calculated by numerical integration, and divided by the strain applied.

These figures refer to the preceding figures, respectively, and represent two examples of thermomechanical simulations carried out in different conditions. In figure $3, \mathrm{~T}_{\mathrm{nr}}$ is perfectly defined by the intersection of the two straight lines. In figure 4, $\mathrm{T}_{\mathrm{nr}}$ does not exist due to the complete recrystallisation between passes. In both cases the temperature $\mathrm{A}_{\mathrm{r} 3}$ is defined by the intersection of the curve with the preceding straight line. However, the temperature $A_{r 1}$ can be defined by the minimum of the curve, which would be an apparent value, or by its real value, which would be given by a point after the minimum and would coincide with the start of the straight part of the curve; which in these figures it has not been possible to draw because the temperature of the final pass was not sufficiently low.

In accordance with the above, it is possible to distinguish four zones with different microstructures, respectively, which have been marked on figure 3 :

- Zone I: corresponds to austenite which recrystallises completely between passes.

- Zone II: corresponds to austenite whose recrystallisation is partially or totally inhibited.

- Zone III: corresponds to the austenite-ferrite transformation.

- Zone IV: corresponds to ferrite and pearlite 
In fact, zone III is broader than is indicated in figure 3, since, as has been mentioned above, the temperature $A_{r 1}$ which is marked is only an apparent value because the true final temperature of the transformation of the proeutectoid austenite is lower than that indicated by the minimum of the parabola.

With regard to $\Delta \sigma$, its value has been determined by making the geometric composition indicated in the above figures. It is given by the length of the vertical segment drawn at $A_{r 3}$ and limited by the prolongation of the zone I straight regression line and the zone II regression line, as is illustrated in figure 3 . The method applied considers that if the austenite were to recrystallise completely between passes until reaching $A_{r 3}$, the slope of the zone II straight regression line would be the same as that of the zone I straight line, and in this case the residual stress would be nil, as in figure 4. In this way it has been possible to measure $\Delta \sigma$ for all the thermomechanical simulations in a quick and precise way, since this magnitude represents better than any other the degree of strengthening of the austenite in the temperature interval $\mathrm{T}_{\mathrm{nr}}-\mathrm{A}_{\mathrm{r} 3}$.

All the values of $T_{n r}, \Delta \sigma, A_{r 3}$ and $A_{r 1}$ were measured on the graphs of MFS versus $1 / T$ for all the deformation conditions tested. These values are shown in table 2 , where it can be seen that while $\mathrm{T}_{\mathrm{nr}}$ and $\Delta \sigma$ decrease as the interpass time increases, $A_{r 3}$ and $A_{r 1}$ remain practically constant. An increase in $\Delta t$ obviously means improving the possibility of the recrystallised fraction increasing between passes with temperatures below $\mathrm{T}_{\mathrm{nr}}$. On the other hand, the values of $T_{n r}$ and $\Delta \sigma$ for one same value of $\Delta t$ were naturally lower when the strain was greater (0.35). This is due to the fact that the increase in the strain accelerates the kinetics of static recrystallisation between passes, this being the variable which, together with the temperature, has the greatest influence on these kinetics. [20; 21; 22]

Figures 5 and 6 illustrate the influence of $\Delta \mathrm{t}$ and the strain on $\mathrm{T}_{\mathrm{nr}}$ and $\Delta \sigma$, respectively. $\mathrm{T}_{\mathrm{nr}}$ decreases considerably with $\Delta \mathrm{t}$ and is always lower for the strain of 0.35 . In the same way, $\Delta \sigma$ decreases with $\Delta \mathrm{t}$ until it reaches zero and is also lower when the strain applied was 0.35 . These results indicate that in order to achieve good strengthening of the austenite during hot rolling, close to pancaking, it is necessary to apply low strains and to reduce the interpass time, as would occur in the finishing strip mill. In plate hot rolling it would be more difficult to achieve pancaking, but a reduction in the interpass times and low strains in the final passes would help to achieve this objective.

Following the geometric procedure noted above for determining $\Delta \sigma$, the accumulated stress can easily be measured at any temperature above $\mathrm{A}_{\mathrm{r} 3}$ and below $\mathrm{T}_{\mathrm{n}}$, thus making it possible to know the gradual grade of strengthening as a function of the temperature. For this it is sufficient to subtract from the zone I regression plot the zone II regression plot for temperatures between $T_{n r}$ and $A_{r 3}$. The results calculated in this way are shown in figures 7 and 8 for strains of 0.20 and 0.35 , respectively. The graphs clearly show the evolution of accumulated stress versus temperature and make it possible to find, either directly or by interpolation, the residual stress that the austenite would have at the end of hot rolling, whatever the temperature at which it finalises.

The $A_{r 3}$ transformation temperature was determined by the intersection of the phase II straight regression line with the parabola, though the real temperature may be assumed to be slightly higher than that given by this intersection. However, both the straight line and the parabola are plotted by regression of points situated at $25^{\circ} \mathrm{C}$ intervals, and this makes it difficult to determine $A_{r 3}$ with greater precision. From table 2 it is deduced that its values are practically constant and independent of the interpass time. Though in principle it would be expectable for $A_{r 3}$ to increase with $\Delta \sigma$, since an increase in the latter also means an increase in the density of dislocations and in the grain boundary relative area, this has not been the case because the decrease in $\mathrm{T}_{\mathrm{nr}}$ with $\Delta \mathrm{t}$ supposes that the austenite suffers more recrystallisation cycles and therefore its size decreases, which would also favour an increase in $\mathrm{A}_{\mathrm{r} 3}$ [20]. Thus certain compensation has taken place, since a decrease in $\Delta \sigma$ or $\mathrm{T}_{\mathrm{nr}}$ means a reduction in the austenite grain size as a consequence of having undergone more cycles of static recrystallisation. Furthermore, there is a third factor that also influences the value of the phase transformation temperature: the cooling rate, which is lower for longer interpass times. In summary, longer interpass times would promote an increase in $\mathrm{A}_{\mathrm{r} 3}$ value caused by smaller cooling rates and smaller $T_{n r}$ values, but also a simultaneous descent in $A_{r 3}$ value due to smaller $\Delta \sigma$ values. The final result has been that $A_{r 3}$ remains practically constant. When the values of $A_{r 3}$ corresponding to the two strains are compared, it is seen that those corresponding to the strain of 0.20 are slightly greater than those corresponding to the strain of 0.35 , the explanation for which would lie in the evolution of the austenite. The combination of the value of $\Delta \sigma$ and the austenite grain size gave rise to more nucleation sites for ferrite when the applied strain was 0.20 than when it was 0.35 .

With regard to the $A_{r 1}$ temperature, the minimum of the parabola has been taken as the representative point, since it has not been possible to determine the real $A_{r 1}$ temperature for the reasons noted above. Nevertheless, by comparison with the values determined by dilatometry, more than $80 \%$ of the proeutectoid ferrite is expected to be transformed between $\mathrm{A}_{\mathrm{r} 3}$ and $\mathrm{A}_{\mathrm{r} 1}$. Their values may be considered to be independent of $\Delta \mathrm{t}$ and their discussion would be similar to the above discussion regarding $A_{r 3}$.

Cooling transformation curves and critical temperatures determined by dilatometry. By means of dilatometry tests, critical cooling temperatures were determined for the aforementioned rates. Though the resulting dilatometry curves are easy to interpret, it is useful to graphically represent the critical temperatures in order to efficiently compare the values determined by this method with the values determined thermomechanically. Fig- 
ures 9 and 10 show two examples of dilatometry curves for the studied steel, along with the plots of the heating curves, though reference will only be made to the cooling curves.

All the critical temperatures have been determined with the help of the derived function, and inspection of the above figures allows different magnitudes to be distinguished. The first temperature in decreasing order $\left(\mathrm{A}_{\mathrm{r} 3}^{\prime}\right)$ represents the real temperature of the start of the $\gamma \rightarrow \alpha$ transformation, which is determined supposing, as a hypothesis close to reality, that the dilatation coefficient of austenite before reaching this temperature is approximately constant and that the meeting point of the curve with a straight line drawn as an extension of the linear part of this curve would give the real value of the transformation temperature [13]. In the same way, the true eutectoid transformation temperature is split into two and the start and finish temperatures are referred to as $\left(A_{r 1}^{\prime}\right)_{s}$ and $\left(A_{r 1}^{\prime}\right)_{f}$, respectively. On the other hand, $A_{r 3}$ and $A_{r 1}$ will be referred to as the apparent start temperatures of the $\gamma \rightarrow \alpha$ transformation and the eutectoid transformation, respectively. The term "apparent" reflects the fact that these temperatures are easy to determine, owing to the notable change in the slope of the dilatometry curve.

Table 3 shows all the values found for the critical temperatures thus determined. As was expectable, an increase in the cooling rate leads to a general decrease in the $A_{r 3}$ and $A_{r 1}$ temperatures.

Though a more detailed study on the kinetics of the $\gamma \rightarrow \alpha$ transformation will be carried out, it is noted that approximately $3 \%$ of the austenite was transformed to ferrite between the temperatures $\mathrm{A}_{\mathrm{r} 3}^{\prime}$ and $\mathrm{A}_{\mathrm{r} 3}$, 80\% between $A_{r 3}$ and $A_{r 1}, 14 \%$ between $A_{r 1}$ and $\left(A_{r 1}\right)_{s}$ and finally $3 \%$ of the austenite was transformed to pearlite. These amounts vary slightly with the cooling rate.

Comparison of critical temperatures determined by thermomechanical simulation and by dilatometry. Figures 11 and 12 show graphs comparing the values of $A_{r 3}$ and $A_{r 1}$ determined by thermomechanical simulation and by dilatometry. Both sets of values are "apparent values", since in the case of the thermomechanical values they are given by a maximum $\left(\mathrm{A}_{\mathrm{r} 3}\right)$, defined by the intersection of the zone II straight line with the parabola, and by the minimum of the parabola $\left(A_{r 1}\right)$. In the case of dilatometry, the reverse is true, and $A_{r 3}$ is given by the minimum of the cooling curve and $\mathrm{A}_{\mathrm{r} 1}$ by the maximum.

Comparison of the values of $\mathrm{A}_{\mathrm{r} 3}$ shows a certain similarity between the values determined by thermomechanical simulation and those determined by dilatometry, with differences that do not exceed $10^{\circ} \mathrm{C}$. On the other hand, the thermomechanical method is not sufficiently precise to reliably determine the real transformation values ( $\left.\mathrm{A}_{\mathrm{r} 3}^{\prime}\right)$, since it is an indirect method of measurement and besides the points determined have a separation of $25^{\circ} \mathrm{C}$.

Comparison of the values of $\mathrm{A}_{\mathrm{r} 1}$ reveals considerable differences. In this case the values determined by dilatometry are notably lower, though in both cases the meaning of $A_{r 1}$ is very similar. In the thermomechanical simulation, $A_{r 1}$ represents the point where the decrease in resistance due to the increase in the transformed ferrite fraction is equal to the increase in resistance due to the drop in the temperature. In dilatometry, $A_{r 1}$ represents the point where the dilatation of the microstructure formed by austenite and ferrite is equal to the compression due to the drop in the temperature. Therefore, while having a similar meaning, the higher values determined by the thermomechanical simulation are due to the great strengthening experienced by the austenite between $A_{r 3}$ and $A_{r 1}$ as it is deformed between these two temperatures, and in short due to the considerable increase in the density of dislocations.

\section{Conclusions}

- Thermomechanical simulation makes it possible to know apparent $A_{r 3}$ and $A_{r 1}$ transformation temperatures at the same time as determining the no-recrystallisation temperature $\left(\mathrm{T}_{\mathrm{nr}}\right)$ and residual stress $(\Delta \sigma)$.

- The accumulated stress or residual stress is a direct and precise measurement of the state of the austenite as a function of the temperature, and is greater the lower the strain applied in each pass.

- In order to obtain strongly deformed austenite microstructures before the $\gamma \rightarrow \alpha$ transformation it is advisable to reduce the interpass time and the magnitude of the strain applied in the final passes.

- The values of $A_{r 3}$ found by thermomechanical simulation are slightly higher when the strain was slightly smaller (0.20), as a consequence of the higher values of $\Delta \sigma$. When these values are compared with those determined by dilatometry, the differences are seen to be less than $5^{\circ} \mathrm{C}$.

- The values of $A_{r 1}$ vary from one method to the other, with the thermomechanical values being greater as a consequence of the residual stress of the austenite between $A_{r 3}$ and $A_{r 1}$. 


\section{References}

[1] Samuel, F.H.; Yu, S.; Jonas, J.J.; Barnes, K.R.: ISIJ Int., 30 (1990), p. 216/25.

[2] Karjalainen, L.P.; Maccagno, T.M.; Jonas, J.J.: ISIJ Int., 35 (1995), p. 1523/31.

[3] Bai, D.Q.; Yue, S.W.; Sun, P.; Jonas, J.J.: Metall. Trans. A, 24 (1993), p. 2151/59.

[4] Kojima, A.; Watanabe, Y.; Terada, Y.; Yoshie, A.; Tamehiro, H.: ISIJ Int., 36 (1996), p. 603/10.

[5] Boratto, F.; Barbosa, R.; Yue, S.; Jonas, J.J.: proc. Int. Conf. On Physical Metallurgy of Thermomechanical Processing of Steels and Others Metals (THERMEC'88), ISIJ, Tokyo, (1988), p. 383/90.

[6] Maccagno, T.M.; Jonas, J.J.; Yue, S.; McCrady, B.J.; Slobodian, R.; Deeks, D.: ISIJ Int., 34 (1994), p. 917/22.

[7] Vega, M.I.; Medina, S.F.; Chapa, M.; Quispe, A.: ISIJ Int., 39 (12), 1999, p. 1304/1310.

[8] Bodnar, R.L.; Adebanjo, R.O.; Hansen, S.S.: Proc. 37th Mechanical Working and Steel Processing Conference, Organized by Iron \& Steel Society, Ontario, Canada, October 1995, vol. XXXIII, p. 735/741.

[9] Radovic, N.; Drobnjak, D.: ISIJ Int., 39 (1999), p. 575/82.

[10]Najafi-Zadeh, A.; Yue, S.; Jonas, J.J.: ISIJ Int., 32 (1992), p. 213/21.

[11]Bengochea, R.; López, B.; Gutierrez, I.: ISIJ Int., 39 (1999), p. 583/91.

[12]Tanaka, T.: Proc. of Int. Conf. Microaloying 95, ed. By. M. Korchinsky, A. j. DeArdo, P. Repas and G. Tither, Pittsburg, USA, (1995), p. 165/81.

[13]Medina, S.F.; Vega, M.I.; Chapa, M.: Mater. Sci.Technol., 16 (2000), p. 163/70.

[14]Sellars, C.M.; Beynon, J.H.: Proc. Conf. on High Strength Low Alloy Steels, ed. By D. Dunne and T. Chandra, South Coast Printers, Wollongong, Australia, (1984), p. 142/150

[15]Gibbs, R.K; Parker, B.A.; Hodgson, P.: Int. Symp. on Low Carbon Steels for the 90's, ed. by R. Asfahani and G. Tither, The Minerals, metals and Materials Society, (1993), p. 173/80.

[16]Hodgson, P.D.; Gibbs, R.K.: ISIJ Int., 32 (1992), p. 1329/38.

[17]Lifshitz; Slyozov, V.V.: J. Phys. Chem. Solids, 19 (1961), p. 35/40.

[18]Turkdogan, E.T:: Iron Steelmaker, 3 (1989), p. 61/75.

[19]Faessel, A.: Rev. Métall,. Cah.Inf.Tech., 33 (1976), p. 875/92.

[20]Sellars, C.M.: Hot Working and Forming Processes, ed. by C.M. Sellars and G.J. Davies; Met. Soc., London, (1980), p. 3/15.

[21]Kwon, O.: ISIJ Int., 32 (1992), p. 350/58.

[22]Medina, S.F.; Quispe, A.: ISIJ Int., 41 (2001), p. 774/81. 
Figure 1. Stress-strain curves corresponding to 20 pass torsion sequence.

Figure 2. Stress-strain curves corresponding to 20 pass torsion sequence.

Figure 3. Dependence of Mean Flow Stress (MFS) on inverse of absolute temperature, according to given schedule.

Figure 4. Dependence of Mean Flow Stress (MFS) on inverse of absolute temperature, according to given schedule.

Figure 5. Interpass time and strain dependence of $\mathrm{T}_{\mathrm{nr}}$.

Figure 6. Interpass time and strain dependence of $\Delta \sigma_{\mathrm{r}}$.

Figure 7. Temperature dependence of $\Delta \sigma_{\mathrm{r}} . \varepsilon=0.20$

Figure 8. Temperature dependence of $\Delta \sigma_{\mathrm{r}} . \varepsilon=0.35$

Figure 9. Dilatometric curve for given cooling and heating rates

Figure 10. Dilatometric curve for given cooling and heating rates

Figure 11. Comparison of the value of $A_{r 3}$ obtained by thermomechanical simulation and by dilatometry.

Figure 12. Comparison of the value of $A_{r 1}$ obtained by thermomechanical simulation and by dilatometry. 
Table 1. Chemical composition of steels used (mass contents in \%).

\begin{tabular}{|l|l|l|l|l|l|l|l|l|l|l|}
\hline $\mathrm{C}$ & $\mathrm{Si}$ & $\mathrm{Mn}$ & $\mathrm{P}$ & $\mathrm{S}$ & $\mathrm{Nb}$ & $\mathrm{Al}$ & $\mathrm{Cu}$ & $\mathrm{Cr}$ & $\mathrm{N}$ & $\mathrm{O}$ \\
\hline 0.09 & 0.23 & 1.1 & 0.021 & 0.007 & 0.017 & 0.005 & 0.015 & 0.066 & 0.017 & 0.0057 \\
\hline
\end{tabular}

Table 2. Values of critical parameters in thermomechanical simulations for different interpass times $(\Delta t)$ and two strains $(\varepsilon)$.

\begin{tabular}{|c|c|c|c|c|c|c|}
\hline Parameter & \multicolumn{6}{|c|}{$\varepsilon=0.20 ; \Delta \mathrm{t}(\mathrm{s})$} \\
\hline & 20 & 30 & 60 & 100 & 200 & 500 \\
\hline $\mathrm{T}_{\mathrm{nr}},{ }^{\circ} \mathrm{C}$ & 970 & 961 & 945 & 919 & 848 & - \\
\hline$\Delta \sigma, \mathrm{Mpa}$ & 45.2 & 29.6 & 25 & 18.8 & 10.2 & 0 \\
\hline $\mathrm{A}_{\mathrm{r} 3},{ }^{\circ} \mathrm{C}$ & 803 & 794 & 805 & 799 & 799 & 798 \\
\hline $\mathrm{A}_{\mathrm{r} 1},{ }^{\circ} \mathrm{C}$ & 748 & 747 & 761 & 756 & 757 & 768 \\
\hline \multirow[t]{2}{*}{ Parameter } & \multicolumn{6}{|c|}{$\varepsilon=0.35 ; \Delta \mathrm{t}(\mathrm{s})$} \\
\hline & 20 & 30 & 60 & 100 & 200 & 500 \\
\hline $\mathrm{T}_{\mathrm{nr}},{ }^{\circ} \mathrm{C}$ & 956 & 939 & 904 & 846 & - & - \\
\hline$\Delta \sigma$, Мра & 16.1 & 16 & 6.3 & 6.1 & 0 & 0 \\
\hline $\mathrm{A}_{\mathrm{r} 3},{ }^{\circ} \mathrm{C}$ & 788 & 798 & 779 & 796 & 789 & 787 \\
\hline $\mathrm{A}_{\mathrm{r} 1},{ }^{\circ} \mathrm{C}$ & 736 & 749 & 738 & 750 & 754 & 749 \\
\hline
\end{tabular}

Table 3. Values of critical temperatures $\left({ }^{\circ} \mathrm{C}\right)$ determined by dilatometry.

\begin{tabular}{|l|l|l|l|l|l|}
\hline Cooling rate, $\mathrm{K} / \mathrm{s}$ & $\mathrm{A}_{\mathrm{r} 3}^{\prime}$ & $\mathrm{A}_{\mathrm{r} 3}$ & $\mathrm{~A}_{\mathrm{r} 1}$ & $\left(\mathrm{~A}_{\mathrm{r} 1}^{\prime}\right)_{\mathrm{s}}$ & $\left(\mathrm{A}_{\mathrm{r} 1}^{\prime}\right)_{\mathrm{f}}$ \\
\hline 1.25 & 809 & 784 & 710 & 634 & 584 \\
\hline 0.84 & 818 & 791 & 722 & 642 & 590 \\
\hline 0.42 & 829 & 800 & 727 & 649 & 602 \\
\hline 0.25 & 842 & 808 & 745 & 656 & 617 \\
\hline
\end{tabular}




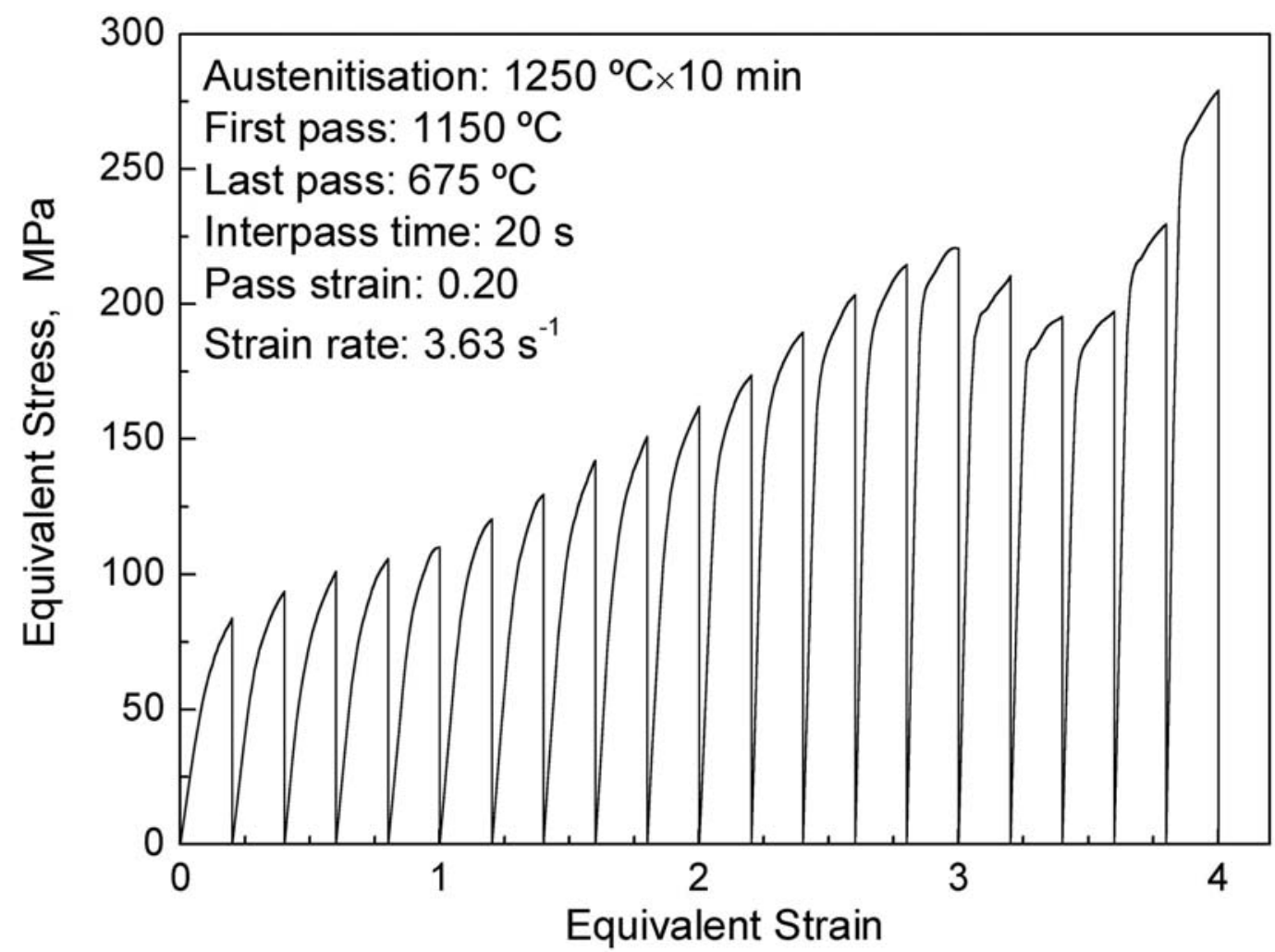

Figure 1. Stress-strain curves corresponding to 20 pass torsion sequence.

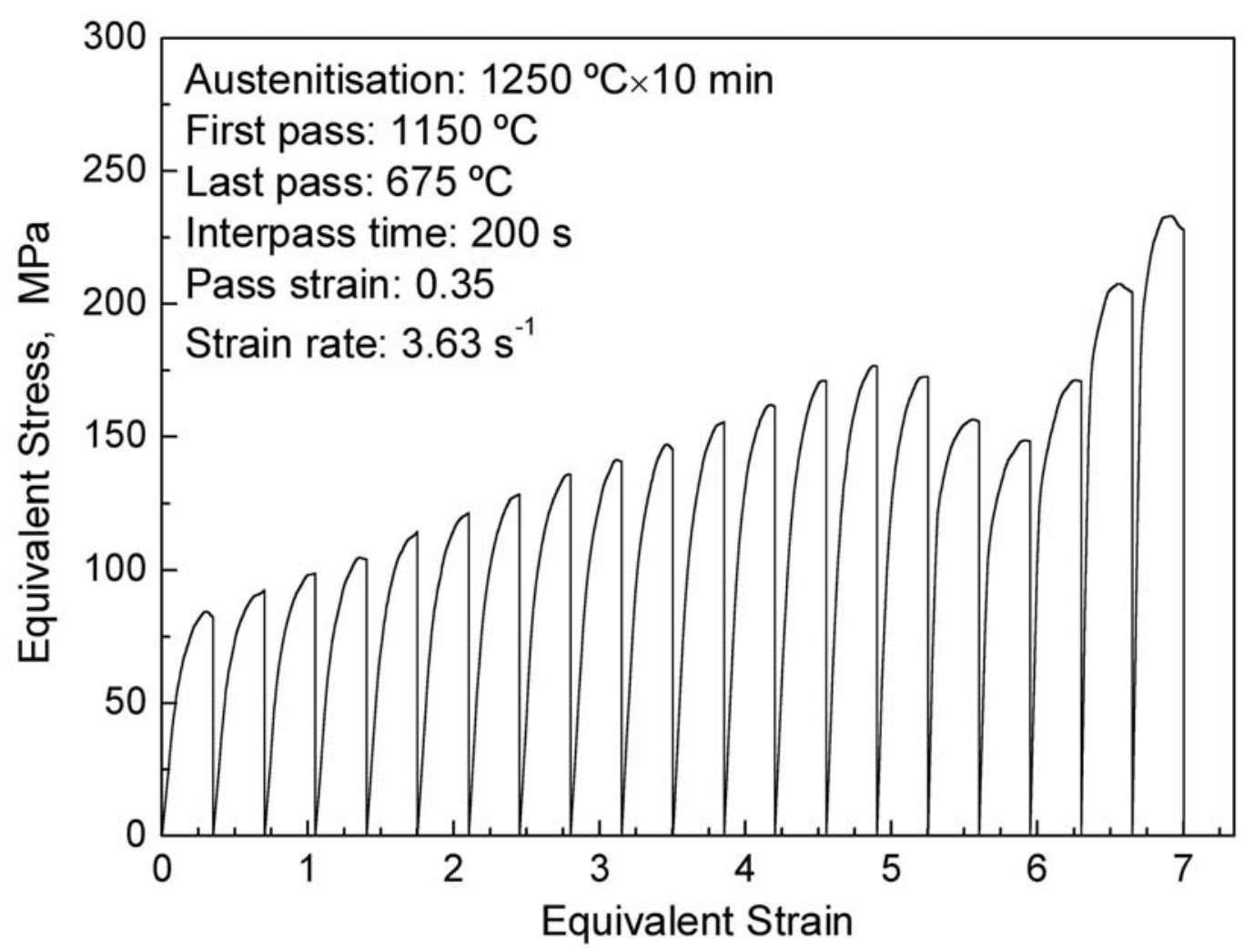

Figure 2. Stress-strain curves corresponding to 20 pass torsion sequence. 


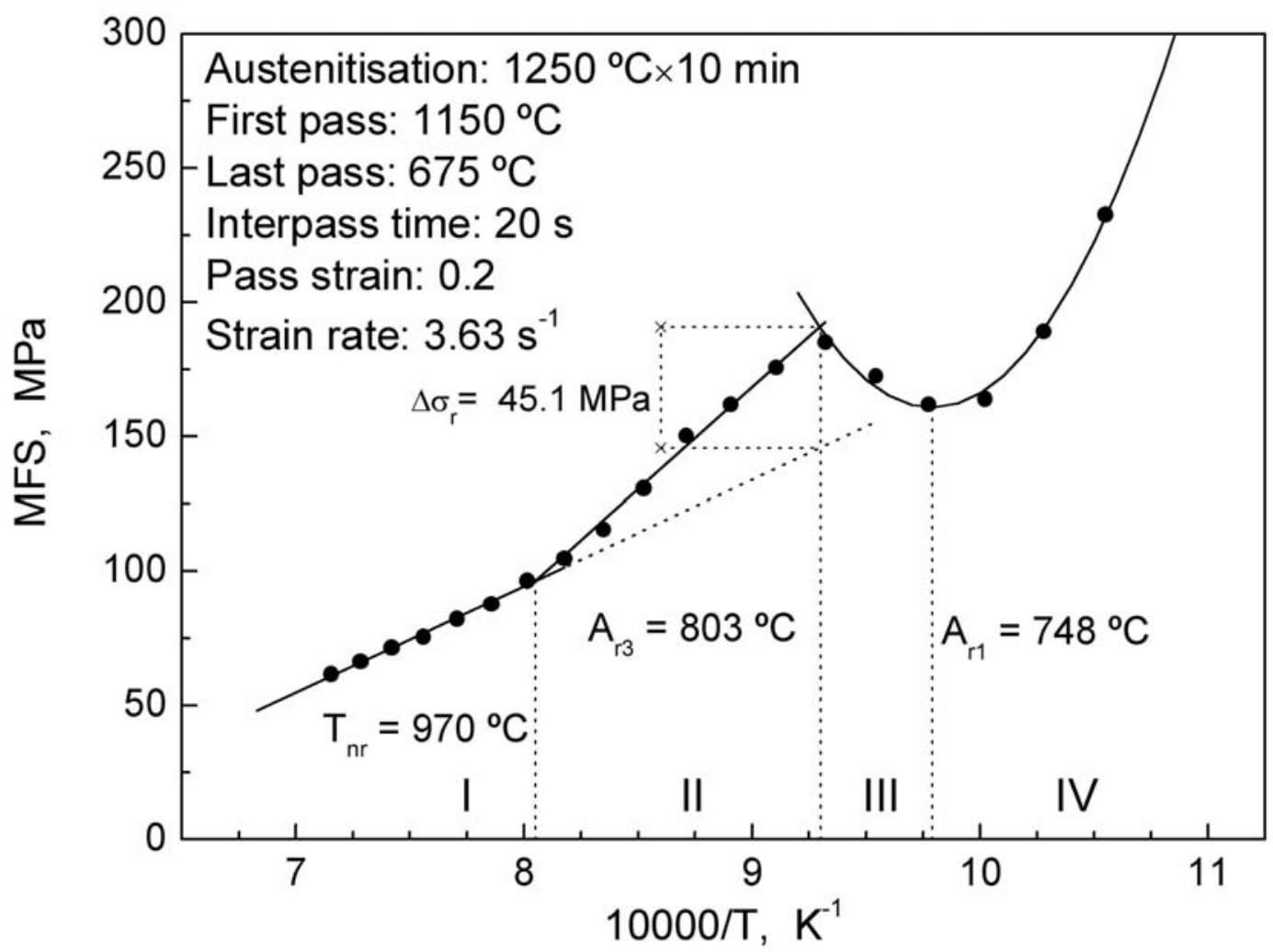

Figure 3. Dependence of Mean Flow Stress (MFS) on inverse of absolute temperature, according to given schedule.

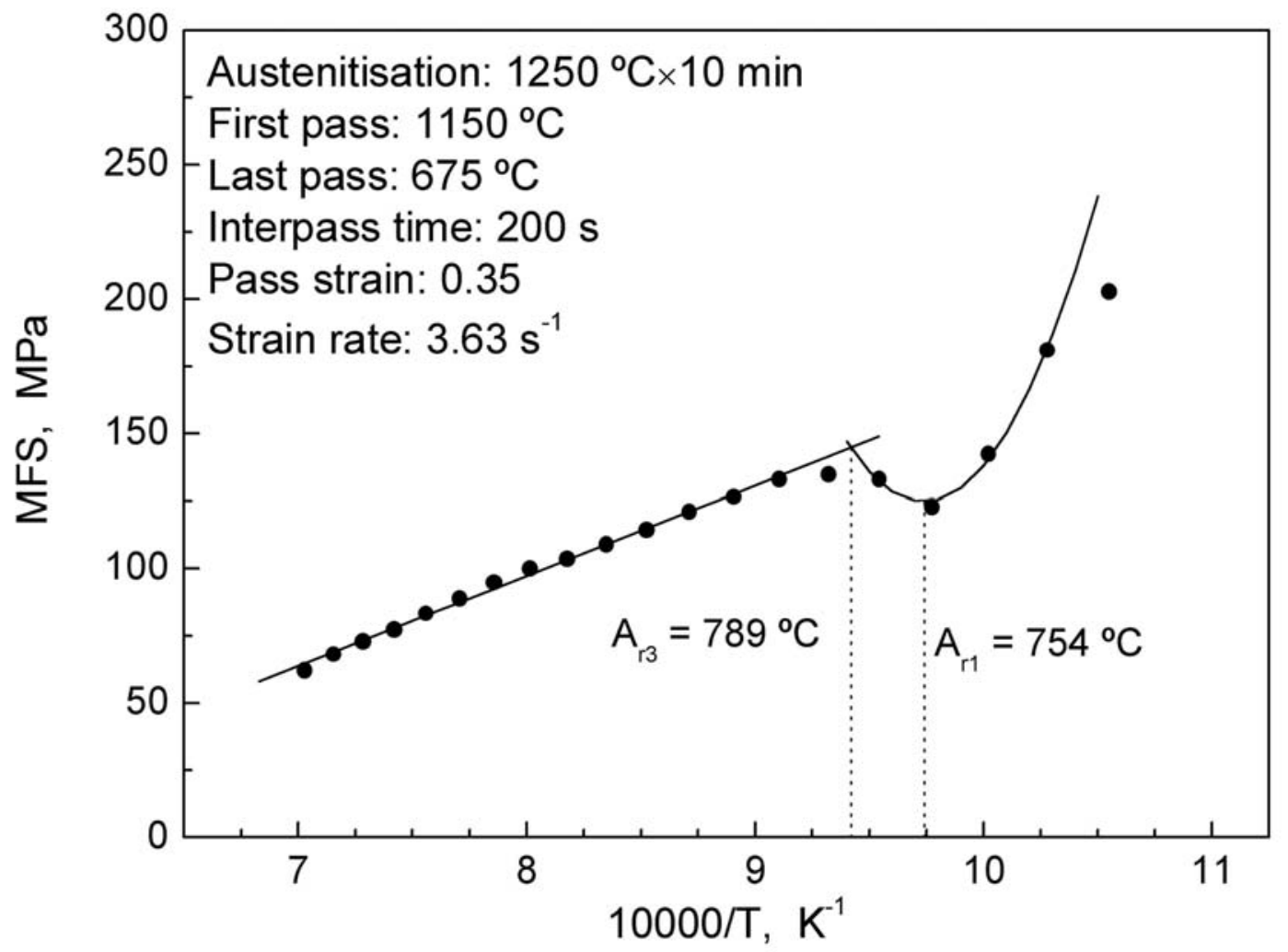

Figure 4. Dependence of Mean Flow Stress (MFS) on inverse of absolute temperature, according to given schedule. 


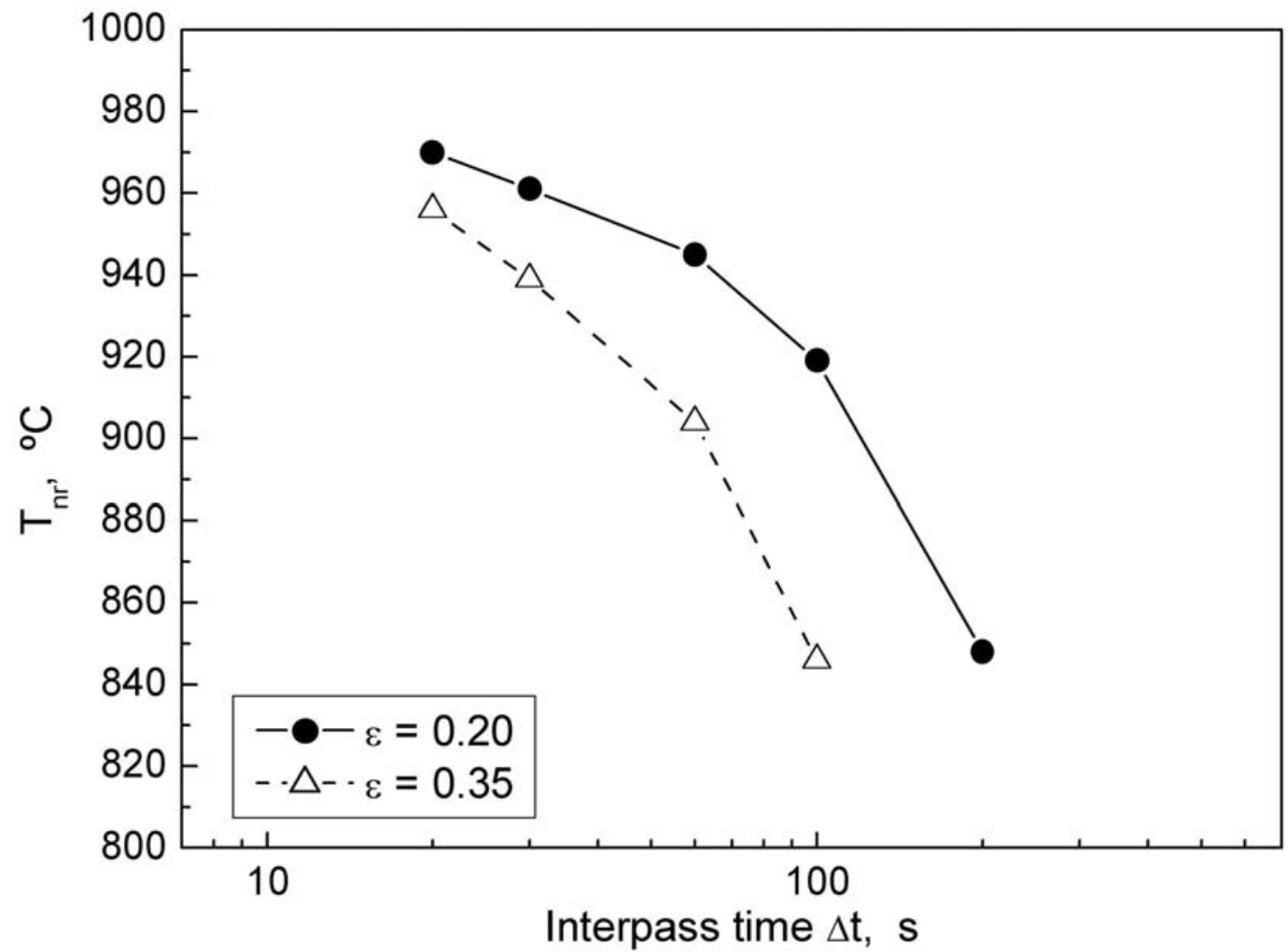

Figure 5. Interpass time and strain dependence of $T_{n r}$.

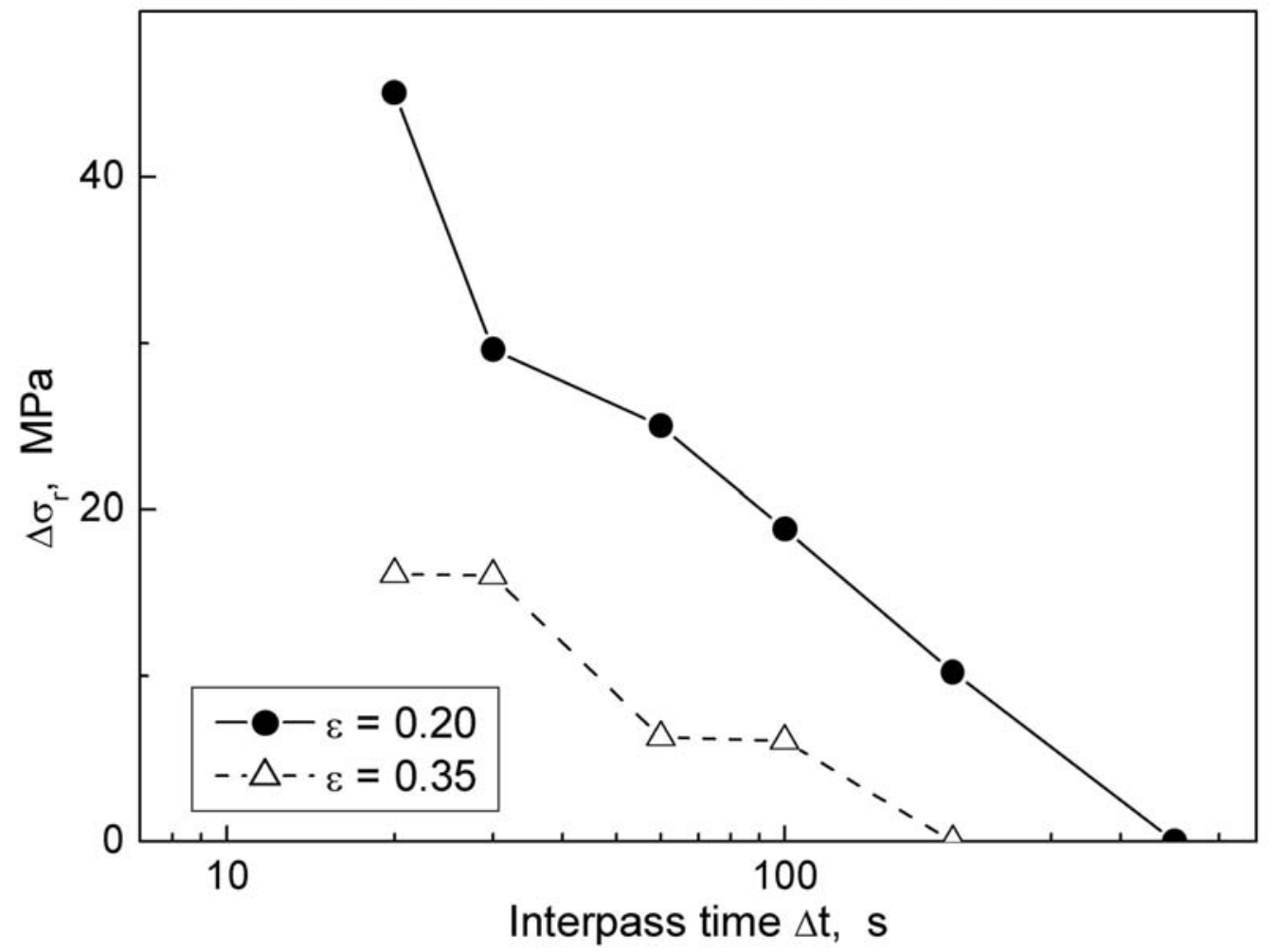

Figure 6. Interpass time and strain dependence of $\Delta \sigma_{\mathrm{r}}$. 


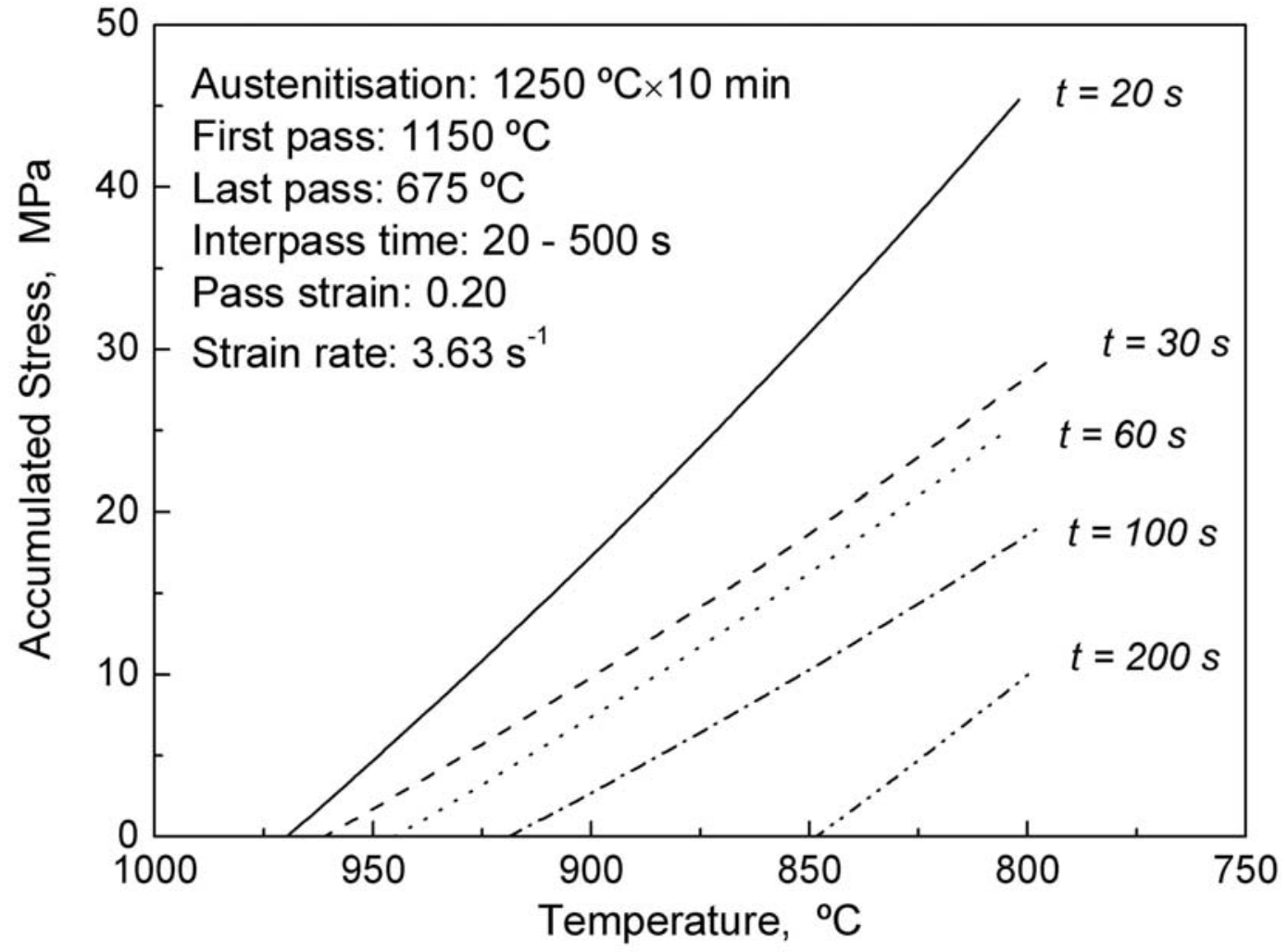

Figure 7. Temperature dependence of $\Delta \sigma_{\mathrm{r}} . \varepsilon=0.20$

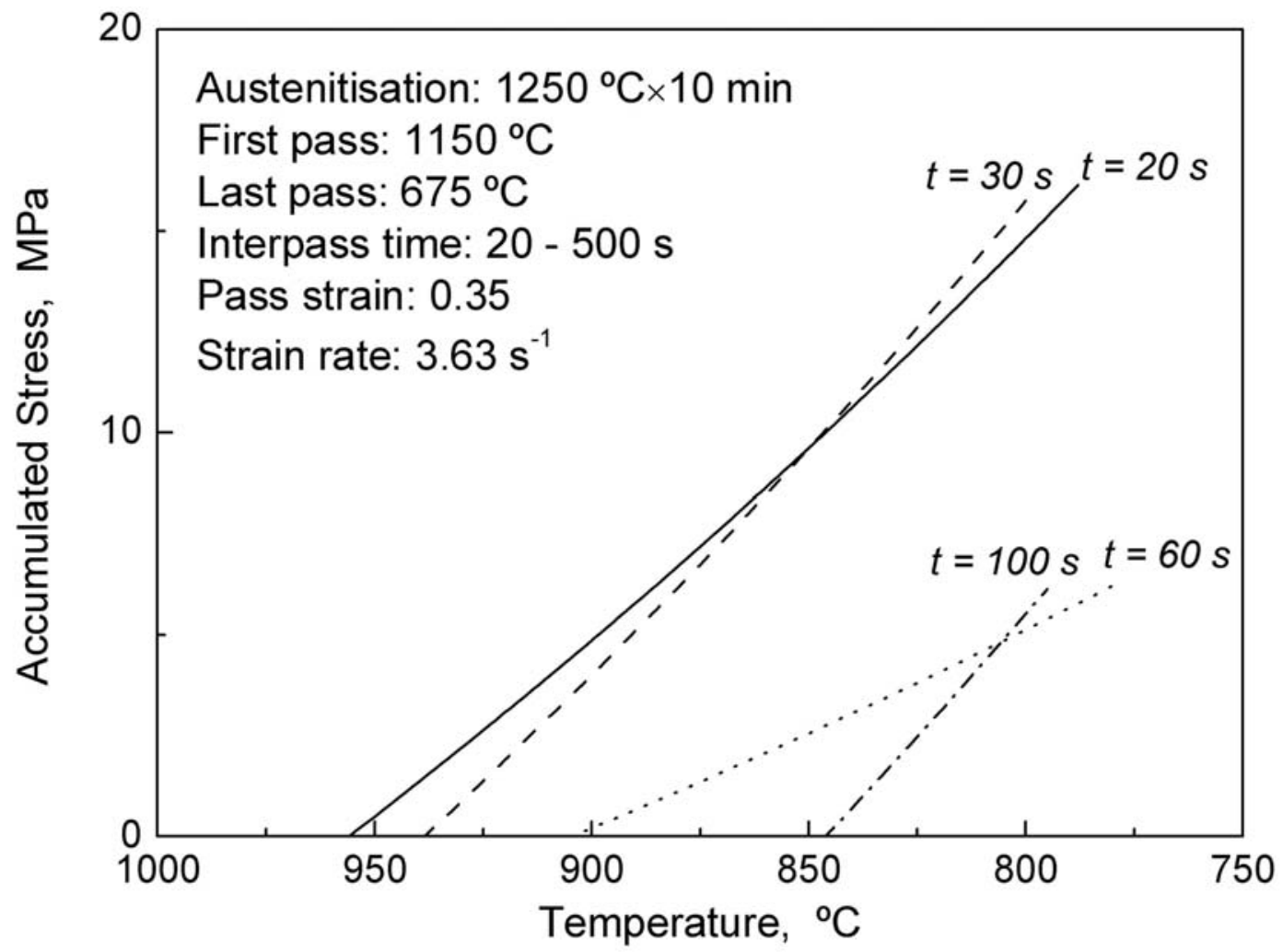

Figure 8. Temperature dependence of $\Delta \sigma_{\mathrm{r} .} \varepsilon=0.35$ 


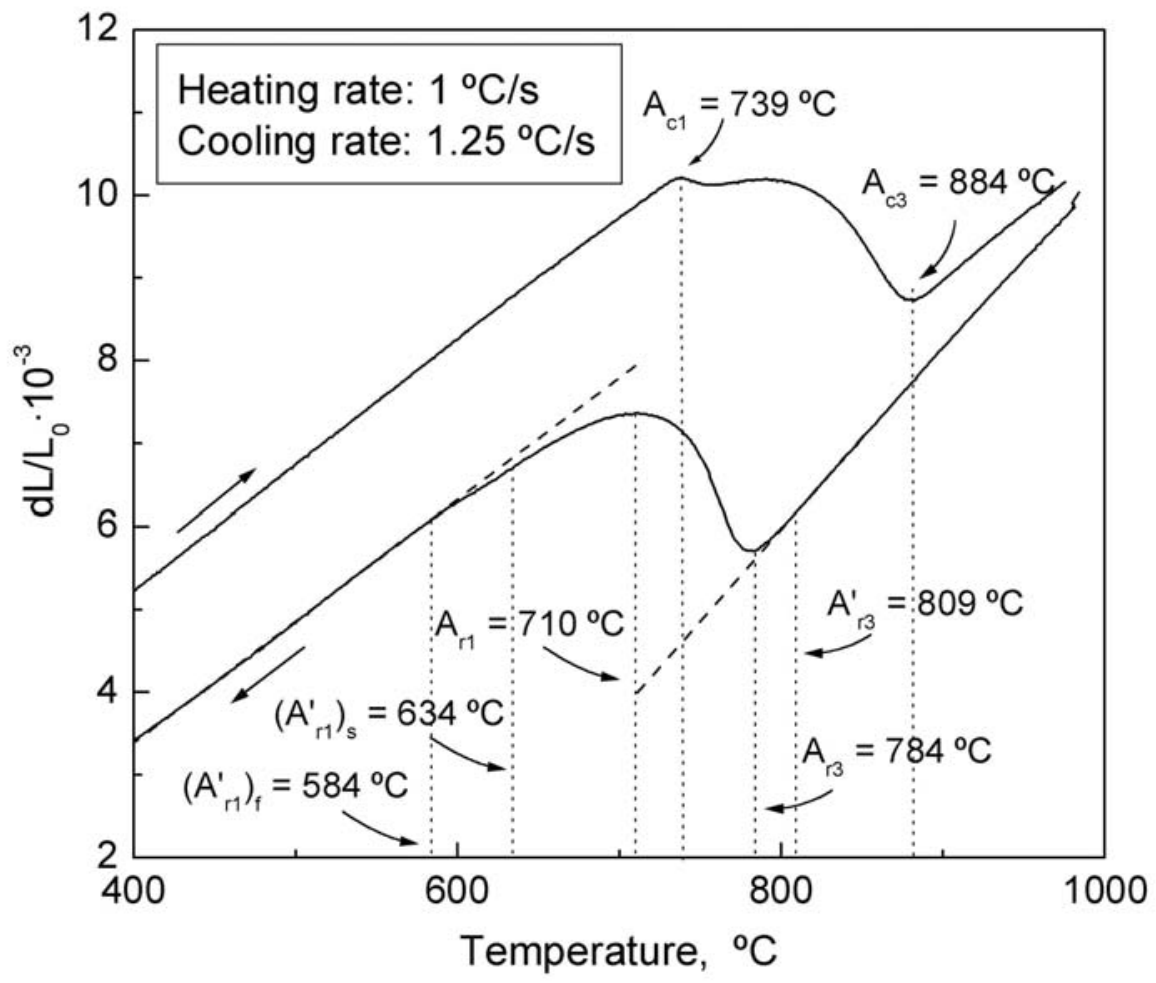

Figure 9. Dilatometric curve for given cooling and heating rates

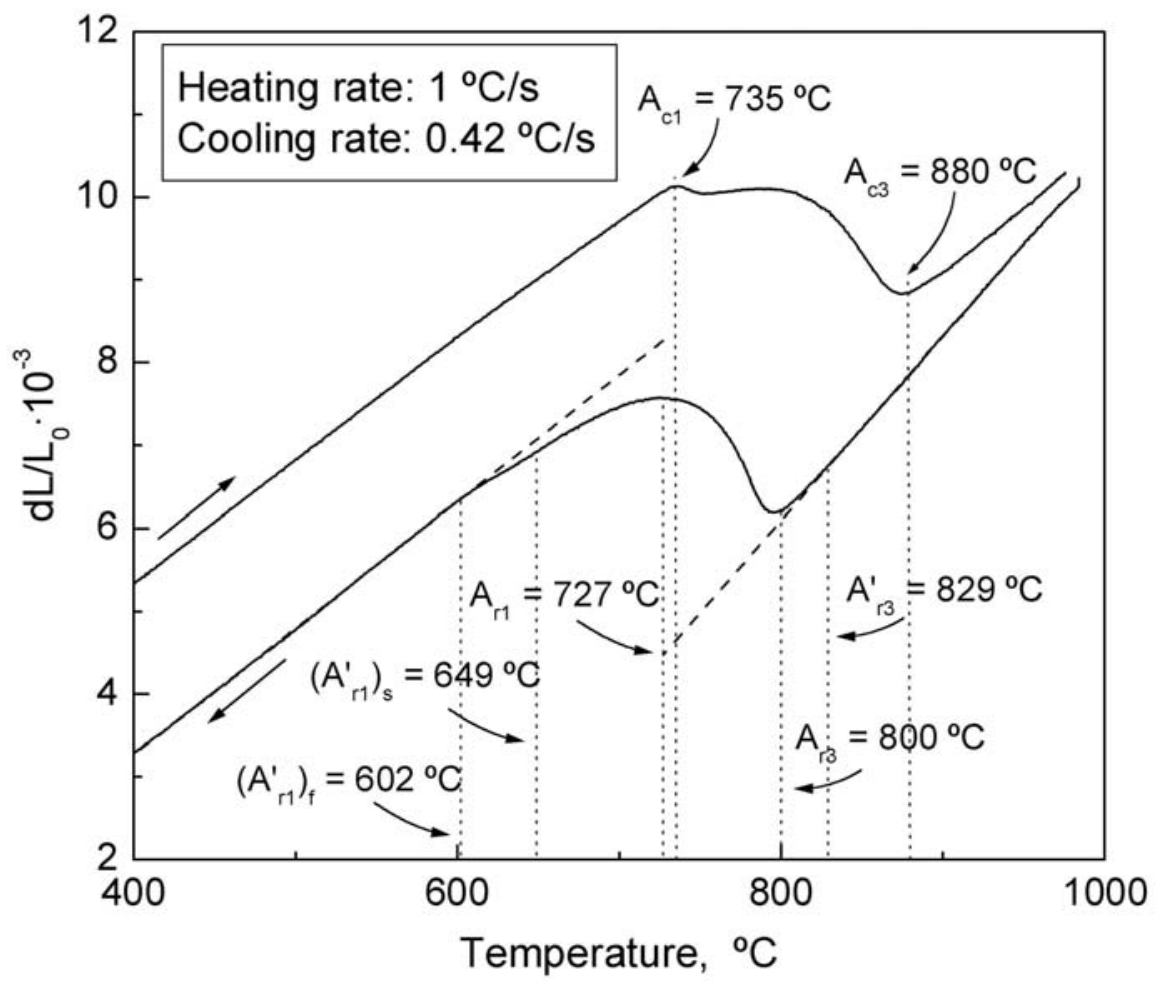

Figure 10. Dilatometric curve for given cooling and heating rates 


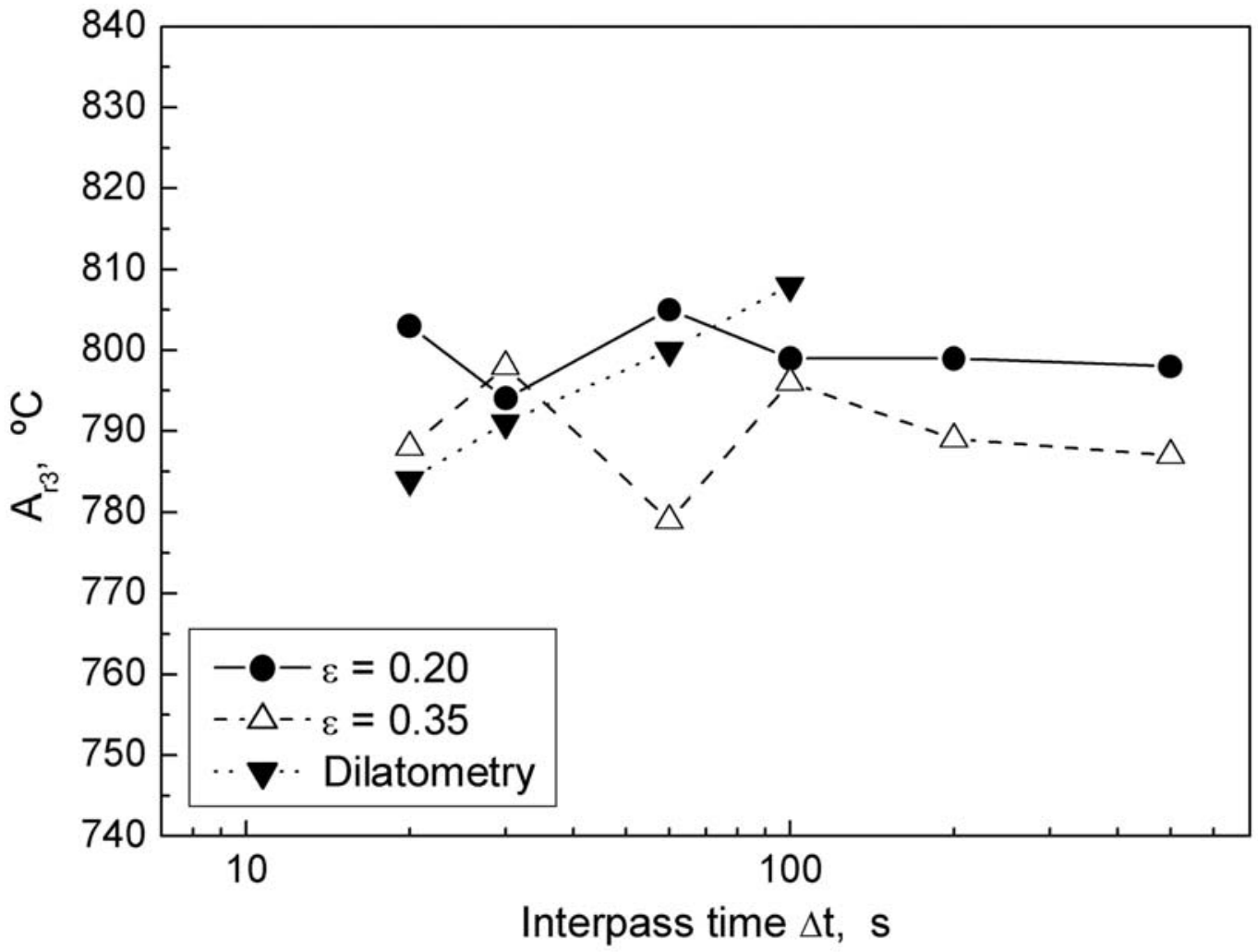

Figure 11. Comparison of the value of $A_{r 3}$ obtained by thermomechanical simulation and by dilatometry.

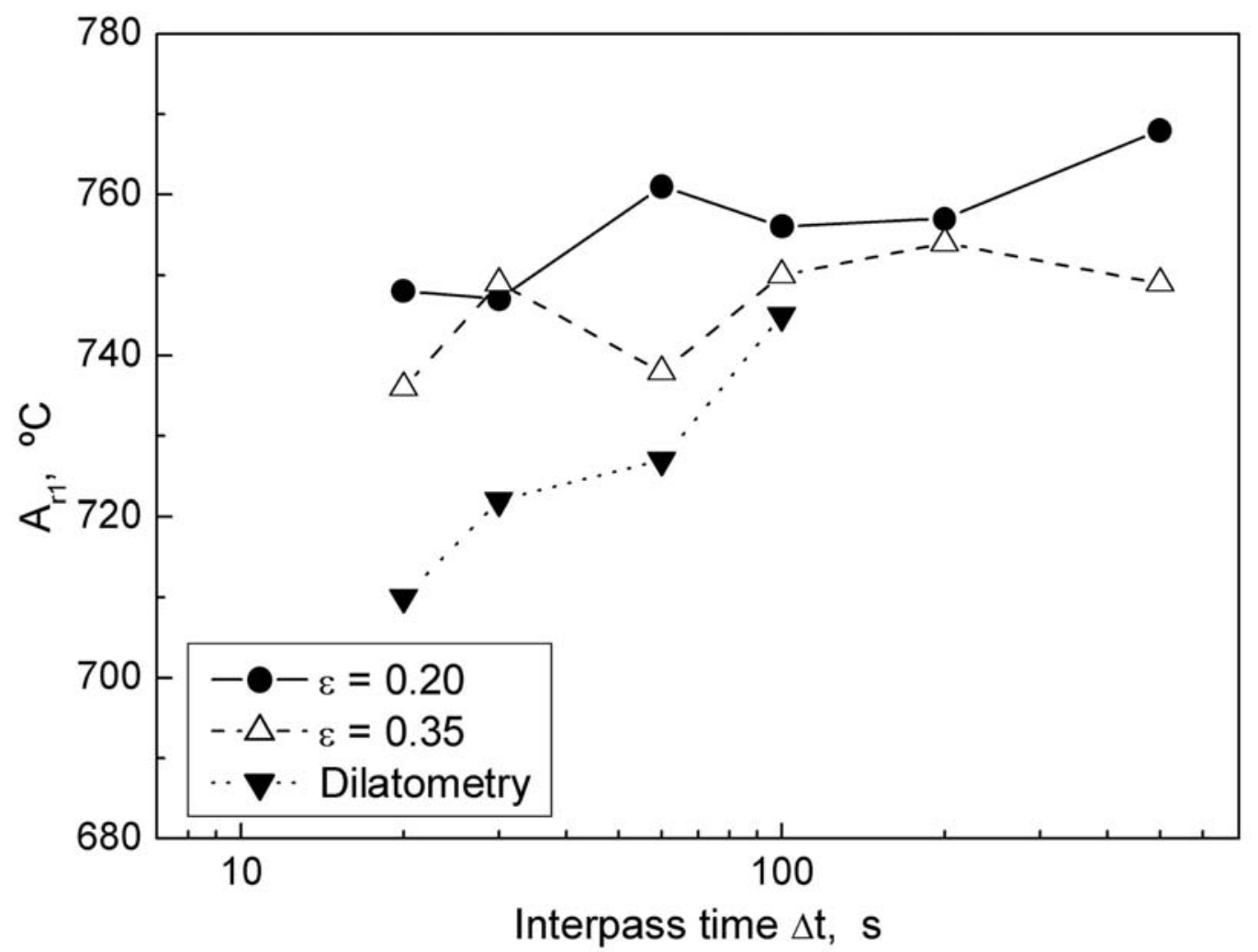

Figure 12. Comparison of the value of Ar1 obtained by thermomechanical simulation and by dilatometry. 